Escolhendo Recordações: Lendo o ritual da festa de aniversário pelo registro fotográfico dos convidados.

Eduardo José Diniz'

ej.diniz@uol.com.br

\title{
Introdução:
}

\section{O experimento}

O segundo aniversário da minha filha se aproximava e com ele a oportunidade de realizar o seguinte experimento: solicitar aos convidados, em princípio todos eles, que trouxessem suas máquinas fotográficas e registrassem a festa. Nenhuma orientação adicional. Apenas tirassem as fotos Ihes ocorressem tirar, quantas quisessem e do que desejassem. Na pior das hipóteses, adviria da experiência, senão um artigo de final de curso, ao menos um múltiplo e variado registro que, esperançosamente, comporia um belo álbum fotográfico da festa de aniversário.

Confiava que seus olhares sobre a festa, ainda que atravessados pelas suas diferentes sensibilidades artísticas, experiências e capacitações técnicas como fotógrafos, seriam dirigidos, principalmente, pela cultura da qual fazem parte. E, como esse marco lhes é comum, a despeito de suas diferenças, são todos brasileiros e residentes no Rio de Janeiro, acreditei que poderia tomar o conjunto das suas fotos como referência do que é importante, o que nos chama o olhar, os pontos focais, que pudessem lançar luz sobre o que compõe, em

\footnotetext{
1 . Doutorando em Ciências Sociais na Pontifícia Universidade Católica do Rio de Janeiro.
} 
suma, o que é o ritual "festa de aniversário". Um pequeno inventário dessa experiência é o que apresento no que se segue.

Foram ao todo 434 fotos feitas por oito convidados, além, é claro, da foto em destaque abaixo que registra-os, eles próprios, os fotógrafos da festa, da minha modesta autoria. Todas as fotos apresentadas nessas páginas fazem parte desse conjunto e a autoria de cada uma delas é referida no anexo Créditos abaixo.

Algumas presenças de destaque no inventário dos registros fotográficos são reveladoras dos componentes principais da festa. A soma dos totais abaixo é bem maior que o total das fotos. Há dupla contagem já que cada foto pode ter sido totalizada em mais de uma categoria. Naturalmente a aniversariante foi muito fotografada (147 fotos) assim como seus pais (198 fotos). Os convidados foram muito registrados (160 fotos), principalmente as crianças (108 fotos), revelando que o aspecto congregacional é da essência do ritual. O local da festa foi bastante registrado (47 fotos, nesse caso incluí apenas as fotos panorâmicas onde a intenção do fotógrafo foi mais mostrar o ambiente do que as pessoas nele, posto que todas as fotos evidentemente foram feitas no local da festa) especialmente a mesa do bolo (30 fotos).

A importância que se dá à comensalidade, ao comer junto, é destacada pela quantidade de registros da alimentação durante a festa, desde a preparação e o serviço às mesas, até o registro de pratos e copos usados, no total, 63 fotos. O destaque nesse tema são os doces (43 fotos) e, dentre eles, o principal é, sem sombra de dúvidas, o bolo (30 fotos). 
O momento da festa mais registrado foi o "parabéns" (42 fotos) o que indica sua importância como o ápice do ritual, assim como a concentração de registros dos elementos e locais que remetem a ele, como o bolo e a mesa que o abriga. Todas essas juntas contam 102 fotos. Outros momentos da festa mereceram destaque como a chegada dos convidados e seu entretenimento, em particular, o das crianças. O teatrinho apenas mereceu 99 fotos. Talvez mais do que o extensivamente registrado, o que não o foi seja tão ou mais revelador. Os principais negligenciados foram os presentes, contando apenas uma única foto.

Esse inventário orientou a divisão desse artigo nos itens abaixo, o que se revelou um processo penoso. Mais do que a profusão de símbolos que os registros invocam, sua polissemia e multivocalidade implicam uma infinidade de abordagens possíveis que se interpenetram umas às outras. (Turner, 2005) As linhas que se seguem expressam não mais que uma tentativa, superficial que seja, de, orientado pelas teorias do ritual, interpelar tal registro fotográfico no sentido de criar uma grande imagem, como que num mosaico, que pudesse não só lançar luz sobre seus significados mas também resumir a experiência da festa e proporcionar um retorno a ela, como é próprio a um bom álbum de fotos. Prossigamos, então, leitores, sem mais esperar. Vocês são meus convidados. Sejam bem-vindos à festa.

\section{Entrada - Preparando a festa \\ O convite}

A preparação da festa de aniversário começa bem antes da sua data. A definição do local, do tema, do menu e da lista de convidados exige uma 
grande dedicação de quem a organiza, tradicionalmente, os pais do aniversariante. O que configura o que poderia ser interpretado como uma longa série de rituais de entrada para o ritual principal, o momento sagrado numa perspectiva durkheimiana, que é a festa. (Durkheim, 2003).

Uma das etapas desse processo chamou-me a atenção sugerindo toda uma linha de interpretação que, embora não pretenda desenvolvê-la em profundidade, é oportuno destacar aqui. Tivemos muito mais dificuldade em definir a lista de convidados para a festa desse segundo aniversário da nossa filha, do que para a do primeiro. Nosso problema era quem excluir da lista com relação aos convidados do ano anterior e as repercussões, evidentemente negativas, que adviriam. Essa dificuldade aponta em dois sentidos principais: por um lado, demonstra quão importante é a congregação para o ritual da festa, principalmente na cultura brasileira que prima por esse "viver nos outros". (Holanda, 2005). Não há festa sem convidados. E numa sociedade aberta é franqueada aos interessados, sujeita a uma infinidade de considerações que em nada facilita o processo, a escolha desses. Não se comemora aniversário sozinho à semelhança dos ritos religiosos. (Mauss e Hubert, 2003).

Por outro lado, aponta para a importância diferenciada do primeiro aniversário. Em particular, do primogênito, como destacou uma informante. Nossa convicção, que tende a um paradigma mais individualista, é de que a festa deve priorizar o entretenimento do aniversariante. Para a festa de um ano, portanto, não pretendíamos preparar nada muito elaborado, dada a incapacidade da aniversariante, naquele momento, de entender e usufruir do 
evento. Nos sentimos, no entanto, como que coagidos $^{2}$ a realizar uma festa muito maior e mais cara do que pretendíamos, afinal, muitos dos nossos familiares e alguns amigos ainda não conheciam a nossa filha. Pelo que pude extrair de algumas conversas recentes e de outros primeiros aniversários que pude observar é reconhecido que a festa de um ano é uma ocasião especial. Tem o status de ser a mais importante das festas de aniversário. Trata-se, numa visão inspirada pela divisão clássica dos ritos de passagem proposta por Van Gennep (Van Gennep, 1978) de uma etapa de reintegração à sociedade ao final de um longo período de liminaridade, desde o nascimento ${ }^{3}$, durante o qual, como diz-se em linguagem popular/tradicional, não se sabe se a criança "vai vingar". O primeiro aniversário é, pois, o momento de apresentação da criança à comunidade de relações da qual fará parte, assim como, de instituição, em se tratando do primogênito, do casal no papel social de pais.

Essa interpretação permite não só entender a importância diferenciada do primeiro aniversário, em particular, o do primogênito, como ainda lança luz sobre o fato, destacado acima no inventário das fotos, dos pais serem, junto do aniversariante, pontos focais da festa.

\footnotetext{
2 "[Q]uando tentamos, mesmo em nosso foro interior, libertar-nos dessas noções fundamentais, sentimos que não somos completamente livres, que algo resiste a nós, dentro e fora de nós. Fora de nós, há a opinião que nos julga; mas, além disso, como a sociedade também é representada em nós, ela se opõe desde dentro de nós a essas veleidades revolucionárias." (Durkheim, 2003: XXIV e XXV). Descrição absolutamente precisa de como me senti pensando na lista de convidados.

Sendo o próprio nascimento um momento de separação radical, assistido por um grupo restritíssimo que inclui, além da mãe e dos facilitadores, quando permitido, apenas um familiar, num total de no máximo 6 a 7 pessoas. Atualmente é aceita e até esperada a participação do pai no parto. Algo que não era recomendável, sendo mesmo interditado, em passado recente. Tal fato, que resiste na relutância ainda presente em certas famílias na participação do pai no parto, pode ser compreendida como sinal de que a proximidade do homem do sagrado é menor que a da mulher. Dessa forma, se houver familiar presente durante o parto, o mais recomendável é que seja uma mulher, em geral entre as mais velhas da família, posto que a sacralidade também aumenta com a idade. (Mauss e Hubert, 2003).
} 


\section{Os presentes}

A maior surpresa que o registro fotográfico da festa reservou foi a virtual ausência dos presentes do conjunto de fotos. Esse é um fato revelador. Tradicionalmente, ao chegar no local da festa, os convidados entregavam os presentes, em seus embrulhos elaborados, diretamente ao aniversariante. Não raro, aguardava-se que ele os abrisse e esperava-se uma reação de surpresa e prazer ao desvelar o conteúdo dos pacotes coloridos e brilhantes.

Atualmente essa prática mudou. Os presentes são entregues na entrada da festa, guardados reservadamente e só serão abertos após a festa. Por um lado, como resultado de adaptação prática à realização das festas num ambiente fora da casa conforme será tratado a seguir. Mas até por isso uma outra interpretação se torna possível.

Tomada em conjunto com a emergência da oferta das "lembrancinhas" às crianças convidadas, prática moderna identificada com a cultura americana, pode-se sugerir que a ausência solene dos presentes do registro fotográfico tem relação com o processo de destradicionalização da cultura brasileira, como sinal da sua aproximação de marcos mais individualistas onde o circuito de débito permanente da dádiva não é muito bem tolerado.

A dádiva ainda é reconhecida, tanto na obrigatoriedade do presente quanto na de se convidar para seu aniversário quem o convidou para o dele, vice versa, o que permite a retribuição do presente, que de acordo com a tradição, deve ser mais ou menos do mesmo valor. O valor do presente é diretamente proporcional à importância da relação que o ofertante estabelece com o presenteado. Mas tanto a instituição da lembrança, uma forma de 
responder à dádiva imediatamente eliminando-se seu circuito, quanto no cuidado em guardar longe das vistas os presentes remetem a esse processo de aumento do individualismo, de modernização, da cultura brasileira.

\section{O local - a casa e a casa de festa}

Realizar-se as festas de aniversário em casas de festa é um procedimento que tornou-se comum em período recente. Tradicionalmente era prática restrita às famílias mais ricas já que este serviço não era ofertado em profusão e os locais disponíveis, como clubes e afins, exigiam produções mais vultosas. A maioria, senão todas, minhas festas de aniversário na infância foram organizadas nas casas onde morei.

Essa alteração recente do local da festa tirando-o do domicílio tem implicações em múltiplos níveis. Por um lado, ressalta o caráter excepcional, fora da rotina do ritual, além de ressaltar a centralidade do entretenimento das crianças, em particular, do aniversariante. Ainda que, mesmo no domicílio, a ambientação em dia de festa seja especial, fora da rotina, posto que a decoração da casa de festa segue o mesmo padrão das festas feitas em casa que é diferente daquela do domicílio em um dia comum: bolas e painéis coloridos, personagens do universo infantil, disposição dos móveis, entre outros.

Por outro lado, pode ser lido como um sinal da transição moderna para uma cultura mais individualista. Ainda que a casa seja tradicionalmente mais sujeita a interdições, por mais sagrada, na cultura brasileira, (DaMatta, 1987) nosso "viver nos outros" nos leva a franquear acesso, aos escolhidos é claro, ao que temos de mais interior, emotivo e espontâneo. (Holanda, 1995). 
Portanto, afastar os convidados da casa num dia excepcional como o da festa é a afastá-los também da intimidade, criar uma cunha entre o convívio social e o universo privado do indivíduo aproximando-se de uma prática mais associada ao universo das culturas mais individualistas.

\section{O local - "altar"}

A parte mais importante do local onde ocorre a festa é o espaço reservado ao "parabéns". Nesse local há sempre uma mesa onde o bolo é posicionado. Todo o espaço nesse entorno, a mesa e suas redondezas, recebe uma decoração bem mais intensa, referente ao tema do evento, de longe a maior concentração de enfeites da festa. Não raro à mesa também estão, além do bolo e das decorações, a maior parte, senão todos, os doces que serão consumidos durante a festa.

Esse espaço está sujeito às maiores interdições em todo o local o que remete ao seu status diferenciado, sua aproximação do sagrado. Durante a festa, antes do "parabéns", não há grande movimentação de pessoas por esse espaço, não se considera uma área adequada para qualquer atividade de entretenimento, nem mesmo para comer. Evidentemente, esse é o espaço que atrai mais atenção dos convidados sendo comum que, ao chegar, passem por ali para verem o bolo, os doces e as decorações. No entanto, a atitude ao fazêlo é costumeiramente de respeitosa reverência. É comum, inclusive, advertirem-se as crianças presentes que não toquem em nada e que o bolo e os doces só podem ser experimentados depois do "parabéns". A frequência com que as crianças esperta e sorrateiramente burlam essas recomendações assim como as reações de desconcerto, risos e vergonha que tais burlas 
ensejam entre os adultos dão mostra de que diante do bolo estamos em terreno sagrado.

\section{Os componentes da festa}

\section{O bolo - a vítima}

Já está claro apenas pela descrição do local da festa e pelo número de fotos em que aparece que o bolo é um elemento central da festa. O que se segue é uma tentativa de interpretar seu significado e papel no ritual.

O bolo é o elemento central da hora do "parabéns", o ápice da festa. É justamente ao redor dele que o aniversariante, os pais e os convidados se reúnem no momento máximo da celebração. Em seguida, o bolo será cortado e dividido entre os presentes para ser comido.

O bolo de aniversário tem paladar obrigatória e marcantemente doce. Seus ingredientes básicos: farinha de trigo, leite, fermento, manteiga e açúcar, são todos, exceto a manteiga, brancos, cor que em várias culturas, incluindo a nossa, é relacionada à pureza.

Curiosamente, todos eles, exceto o leite, passam por processos, evidentemente intencionais, de descoloração para tornarem-se brancos posto que apresentam, na forma mais básica de sua apresentação, coloração mais escura, amarronzada. Nos bolos de aniversário, ao contrário dos de casamento, onde aliás a questão da pureza é mais importante, é aceitável a utilização de ingredientes que Ihe confiram outras colorações e que apeteçam ao paladar infantil, por exemplo, o chocolate. A combinação desses ingredientes é levada por um tempo determinado ao forno, o que remete a ideia 
de útero e de gestação. Depois de pronto, "recém-nascido", o bolo é então decorado, "vestido" com suas coberturas, recheios e adereços. O principal é a vela, uma para cada ano vivido pelo aniversariante ou o algarismo que a eles corresponda. E voilá, está pronto. É muito usual e representativo que entre os adereços conste o nome do aniversariante escrito no bolo.

O significado do bolo na cerimônia já pode ser intuído apenas pela descrição do seu preparo, seus adereços e sua centralidade no ritual. Sugiro aqui que o bolo é a vítima que representa o aniversariante e os pais, os sacrificantes, num ritual de sacrifício. Posso destacar, desde já, quatro pontos já apresentados em defesa desse argumento, ainda que só possa desenvolvêlo plenamente a seguir, adicionando mais elementos à alquimia que empreendo nesse ensaio.

São eles:

i) O bolo, como o aniversariante, é um dos pontos focais da festa sendo o centro do espaço e seu momento mais sagrados;

ii) O nome do aniversariante é comumente escrito no próprio bolo;

iii) Seu paladar e ingredientes remetem a pureza e doçura, ambas características desejáveis, ideais para as crianças na nossa cultura;

iv) E a presença obrigatória sobre o bolo das velas ${ }^{4}$, que em diversas culturas, inclusive a nossa, remetem quando acesas a

\footnotetext{
$4 \quad$ Segundo Lima (1996), Lutero desaconselhou a utilização de velas na missa protestante por dois motivos principais. Em primeiro lugar, porque as considerava como parte dos paramentos que o ascetismo requeria limitar ao mínimo. Em segundo lugar, porque considerava um erro o dogma católico
} 
ideia de organismo vivo, mais abstratamente à própria vida, o inverso oposto quando apagadas, são dispostas segundo o número de anos vividos pelo aniversariante.

\section{$O$ aniversariante e os pais - os sacrificantes}

O número de fotos deixa claro: o aniversariante e os pais são os pontos focais da festa. Mas para entender plenamente seu protagonismo cabe abordar o significado da festa. O aniversário é um rito cíclico anual. Como tal trata-se de uma festividade, um tempo fora da rotina, que serve de marca ritual da passagem do tempo. Mais ainda, é também um rito de passagem que marca $o$ desenvolvimento social do indivíduo. (Leach, 2006).

É interessante notar que uma cultura que concebe o coletivo como a soma de suas partes constituintes, os indivíduos, desenvolva um ritual em que tudo é organizado para convergir em direção a um indivíduo em particular com o propósito tanto de marcar as fases do desenvolvimento pessoal como, mais ainda, para marcar a própria passagem do tempo.

No entanto, como evidência do caráter mais coletivista e hierarquizado da nossa cultura, por oposição, por exemplo à cultura americana, o aniversariante, pelo menos até a atingir a maturidade sexual, a adolescência, não comemora seu aniversário apenas entre os seus iguais. Os iguais são importantes na festa brasileira, como evidencia a quantidade de fotos das

da transubstanciação. Para Lutero a repartição do pão e do vinho é um ritual de comunhão, um símbolo da comensalidade, da união da congregação e não um sacrifício como está implicado se os objetos da comunhão são, de fato, o corpo e o sangue de Cristo. Por essa segunda objeção fica sugerida novamente a relação, na cultura católica, entre as velas e a vida. 
crianças convidadas à festa e do entretenimento voltado a elas. Mas é a família ${ }^{5}$, em particular, os pais, junto ao aniversariante e, evidentemente, as relações que estabelecem entre eles, hierárquicas, cabe dizer, os pontos focais da festa.

Por outro lado, como o indivíduo não pode dar, nem a si próprio nem a alguém, algo que não tem, a orientação da festa aos pontos focais implica num fluxo de atenção, de energia e de sentido, da sociedade, representada pelos convidados, para os sacrificantes, o aniversariante e seus pais. "Na medida em que participa da sociedade, o indivíduo naturalmente ultrapassa a si mesmo, seja quando pensa, seja quando age." (Durkheim, 2003: XXIV). Como já foi antecipado acima, a festa é o ritual que transmite da sociedade aos sacrificantes energia e status sociais novos. Ao aniversariante confere a oportunidade de chancelar socialmente seu desenvolvimento pessoal. Já os pais são instituídos, e periodicamente confirmados, no papel social de pais. Retornarei a esse ponto a seguir para torná-lo mais denso quando tratar do ápice da festa, o assassínio ritual da vítima.

\section{O sacrifício}

\section{Chegou a hora de apagar as velinhas!}

Ao valorizar o aspecto congregacional da comunhão na missa, como fazem os protestantes, reforça-se, numa cultura individualista, a ideia de um laço social, posicionado no universo das necessidades fisiológicas pela

\footnotetext{
5 Repare na foto $\mathrm{n}^{\circ} 9$, do momento do "parabéns". No lado esquerdo, próximo à mesa do bolo e, consequentemente, da aniversariante e seus pais, ou seja, próximo ao local e no momento mais sagrados estão os avós, tia e prima.
} 
comensalidade, que os une. Valorizar o caráter sacrificial da comunhão, como os católicos, faz referência aos mesmos laços sociais mas carrega mais nas tintas, acrescentando doses generosas de culpa que devem ser purgadas pela lembrança constante e pela encenação periódica do sacrifício do próprio filho que o personagem dos nossos mitos de origem, o instituidor da nossa sociedade, o grande patriarca, o "pai de todos", dedicou a nós. Vale dizer, o sacrifício que se fez necessário para nos constituir como sociedade.

Vários são as evidências presentes no ritual do aniversário, em particular, a centralidade do "parabéns", as ações e elementos que se relacionam a ele, que permitem interpretá-lo como um sacrifício. A principal delas é a aproximação, a transubstanciação, do bolo no aniversariante. O bolo em si, duas características, componentes assim como seu processo de preparação já foram abordados acima. O que interessa agora para completar o quadro são as ações desempenhadas no momento no momento do assassinato ritual, o ápice da festa, o "parabéns".

O "parabéns" se inicia com a convocação de todos os participantes para aproximarem-se do altar, o local mais sagrado da festa, o entorno da mesa do bolo. Acendem-se as velas, o que pode ser interpretado como última etapa do processo de trazer o bolo à vida. Prossegue-se, imediatamente, ao cântico tradicional do "parabéns". A letra cantada remete à vida do aniversariante, congratulando-o pela graça de estar vivo e expressando o desejo coletivo esta seja longa e feliz. É essencial que todos os presentes juntem as vozes em coro ao compasso das próprias palmas, essas ainda mais obrigatórias que o canto, o que marca a participação ativa, energética/energizante, da congregação, dos convidados, a própria sociedade presente ao ritual. Moto contínuo, terminada a 
canção, o aniversariante sopra sobre o bolo, apagando as velas. É necessário que seja o aniversariante a soprar ainda que seu sopro porventura não seja, em virtude do estágio de seu desenvolvimento, suficientemente forte e/ou corretamente direcionado para apagar as velas. Nesse caso, um dos pais, os dois ou ainda alguma pessoa próxima ajudam, no mais das vezes também soprando, a apagá-las. Esse parece-me o ponto crucial. Apagar as velas remete a ideia de morte. Apagá-las com um sopro também diz muito a respeito do significado do ritual. O sopro está relacionado a vida. ${ }^{6}$ Assim, se apagar as velas simboliza o suicídio ritual do aniversariante, seu sopro pode ser interpretado como a transferência da sua vida ao próprio bolo que, sendo sopro a última etapa do processo, assume a identidade do próprio aniversariante. Procede-se em seguida à divisão do bolo em fatias, novamente remendo à morte, a um esquartejamento ritual. É desejável, sempre que possível ${ }^{7}$, que o próprio aniversariante corte a primeira fatia, ou seja, faça a primeira incisão no bolo. O que remete novamente ao suicídio, de forma que é o próprio aniversariante acumula o papel de sacrificante e o de sacrificador.

O bolo é então distribuído aos convidados. Ao primeiro pedaço é atribuído valor especial, posto que deve ser servido pelo próprio aniversariante, novamente sempre que possível, à pessoa mais importante e querida presente à festa. Muita tensão e constrangimento resultam dessa obrigação. Como a primeira fatia é necessariamente única e os entes próximos são vários, uma

\footnotetext{
Passagem muito conhecida do Gênesis (Gen. 2:7) afirma: "E formou o Senhor Deus o homem do pó da terra, e soprou em seus narizes o fôlego da vida; e o homem foi feito alma vivente."

Cabe destacar dois pontos aqui: Primeiro, se o aniversariante não conseguir sozinho cortar o bolo é costumeiro auxiliá-lo, segurando-lhe e dirigindo-lhe a mão que empunha o objeto cortante, preferencialmente a substituí-lo simplesmente nessa função. Segundo, é também comum que se proceda o primeiro corte do bolo de forma diferente, de baixo para cima, ao que se faria habitualmente, de cima para baixo. A referência aqui é à má sorte que adviria de orientar o corte para baixo. Pesa sobre as regiões localizadas abaixo o status de ordinárias, sujas, em resumo, profanas. Ao passo que acima estão regiões sagradas.
} 
escolha crucial deve ser feita pelo aniversariante. Ao menos dois parentes muito próximos, os pais, devem estar presentes, quando possível, evidentemente. Ambos devem não só presentes à festa mas próximos ao aniversariante durante todo o "parabéns". Sem qualquer um deles à mesa do bolo, caso ambos estejam presentes à festa, o "parabéns" não é iniciado. Normalmente cabe à mãe essa honraria. Mais um exemplo da sacralidade feminina. Não dar à mãe o primeiro pedaço é interpretado como um descumprimento da obrigação suprema de amá-la sobre todas coisas.

Os convidados comem, então, a fatia que lhes coube do bolo e em seguida os demais doces. Não é considerado normal recusar-se a comer o bolo ao passo que todos os outros alimentos servidos são opcionais. O simbolismo é bem direto. A sociedade, na figura dos convidados, absorve radicalmente o aniversariante no seu interior. Ao mesmo tempo, reforça a desejo coletivo, que é para o aniversariante uma obrigação individual, que exiba as qualidades intrínsecas do bolo, principalmente, sua pureza e doçura. Esta última mais importante e reveladora posto que pode se entendida como a não rejeição ou a sujeição suave, pacífica, do indivíduo às regras sociais.

\section{A saída}

\section{O fim da festa}

Findo o "parabéns" e comido o bolo a festa rapidamente se desmobiliza. Não há rituais relevantes de saída, além das saudações habituais de despedida. Tal fato indica que o ritual de aniversário promove uma alteração nos seus participantes, qual seja, a integração do aniversariante na sociedade 
e nas suas normas, que se deseja manter não sendo necessário nem necessário desmobilizar-se do estado de sacralidade. (Mauss e Hubert, 2003) Acaso não é essa a sensação do final da festa, um sentir-se pleno?

Trata-se, portanto, de um ritual que simboliza a predominância da sociedade sobre o indivíduo na nossa cultura, que seria o estado ideal, sagrado, dos seus componentes. Estado esse que precisa ser renovado periodicamente pelo ritual da festa.

\section{Referências bibliográficas}

DAMATTA, R. A Casa \& a Rua. Espaço, cidadania, mulher e morte no Brasil. Rio de Janeiro: Guanabara, 1987.

DURKHEIM, E. As formas elementares da vida religiosa, São Paulo: Martins Fontes, 2003.

HOLANDA, S. B. de. Raízes do Brasil. São Paulo: Companhia das Letras, 2005. LEACH, E. R. Repensando a antropologia. São Paulo: Perspectiva, 2006.

LIMA, H. Lutero e a reforma protestante. Mimeo. 1996.

http://www.athanazio.com/2006/07/23/lutero-e-a-reforma-protestante/

MAUSS, M. Sociologia e antropologia, São Paulo: Cosac \& Naify, 2003. MAUSS, M. e HUBERT, H. Sobre o Sacrifício. São Paulo: Cosac Naify, 2005.

TURNER, Victor. Floresta de Símbolos: aspectos do Ritual Ndembu. Niterói: Editora da Universidade Federal Fluminense, 2005. 